\title{
Phytochemical compounds of anise hyssop (Agastache foeniculum) and antibacterial, antioxidant, and acetylcholinesterase inhibitory properties of its essential oil
}

\author{
Ivan G. Ivanov ${ }^{1 *}$, Radka Z. Vrancheva ${ }^{2}$, Nadezhda T. Petkova $^{1}$, Yulian Tumbarski ${ }^{3}$, Ivayla N. Dincheva ${ }^{4}$, Ilian K. Badjakov ${ }^{4}$ \\ ${ }^{1}$ Department of Organic Chemistry and Inorganic Chemistry, University of Food Technologies, Plovdiv, Bulgaria. \\ ${ }^{2}$ Department of Analytical Chemistry and Physical Chemistry, University of Food Technologies, Plovdiv, Bulgaria. \\ ${ }^{3}$ Department of Microbiology, University of Food Technologies, Plovdiv, Bulgaria. \\ ${ }^{4}$ AgroBioInstitute, Agricultural Academy, Sofia, Bulgaria.
}

\section{ARTICLE INFO \\ Received on: 17/10/2018 \\ Accepted on: 07/01/2019 \\ Available online: 28/02/2019}

Key words:

Agastache foeniculum, essential oil, pentacyclic triterpenes, antimicrobial activity, antioxidant activity, rosmarinic acid.

\begin{abstract}
Agastache foeniculum (Pursh) Kuntze (anise hyssop) is known as a medicinal and flavoring spice plant. The aim of this research was gas chromatography-mass spectrometry (GC-MS) analysis of anise hyssop essential oil and analysis of radical scavenging ability, antimicrobial activity, and acetylcholinesterase inhibitory activity. Phytochemical composition of anise hyssop wastes and the aqueous extract obtained after steam distillation was investigated. Eight compounds were identified in essential oils by GC-MS analysis, as the major ones were phenylpropenoids [estragol- $93.45 \%$ of total ion current (TIC), eugenol $-0.15 \%$ of TIC, and methyl isoeugenol $-2.48 \%$ of TIC]. In the anise hyssop wastes extract, four pentacyclic triterpenes were identified (betulin $-36.1 \mathrm{mg} / \mathrm{g}$, betulinic acid -2.4 $\mathrm{mg} / \mathrm{g}$, oleanolic acid- $160.0 \mathrm{mg} / \mathrm{g}$, and ursolic acid $-6.7 \mathrm{mg} / \mathrm{g}$ extract). Rosmarinic acid (50.6 mg/g extract) and flavonoids - myricetin $(0.5 \mathrm{mg} / \mathrm{g})$, luteolin $(0.9 \mathrm{mg} / \mathrm{g})$, and apigenin $(0.6 \mathrm{mg} / \mathrm{g})$ were detected by high-performance liquid chromatography with diode-array detection analysis of aqueous extract. The anise hyssop essential oil showed strong radical scavenging ability $\mathrm{IC}_{50}-6.54 \mu \mathrm{l} / \mathrm{ml}$. The results obtained from antimicrobial screening revealed that essential oil possessed inhibitory activity against Staphylococcus aureus ATCC 25923, Curtobacterium flaccumfaciens PM_YT, Listeria monocytogenes, Bacillus subtilis ATCC 6633, Salmonella sp., Escherichia coli ATCC 8739, Proteus vulgaris, Pseudomonas aeruginosa ATCC 9027, Klebsiella pneumoniae, and Candida albicans, while Enterococcus faecalis remained unaffected.
\end{abstract}

\section{INTRODUCTION}

Agastache foeniculum (Pursh) Kuntze [known as Lophanthus anisatus (Nutt.) Benth.] is a perennial herbaceous plant from Lamiaceae family. This plant can also be found under the common names, such as the fennel giant hyssop, anise hyssop, or "Mexican mint." Anise hyssop is cultivated in Moldova, Romania, Ukraine, and Russia (Chumakova and Popova, 2013). This honey-

\footnotetext{
*Corresponding Author

Ivan G. Ivanov, Department of Organic Chemistry and Inorganic Chemistry, University of Food Technologies, Plovdiv, Bulgaria. E-mail: ivanov_ivan.1979@yahoo.com
}

bearing plant is used for the production of essential oil. The anise hyssop leaves are also used for infusions, food flavoring, and for different type low-alcohol drinks (Zhekova et al., 2010). In traditional medicine, Lophanthus anisatus finds applications for acute respiratory diseases, functional disorders of the gastrointestinal tract, and inflammatory diseases of the urinary system. Externally, the plant is used for dermatitis of fungal origin, seborrhea, used to strengthen and grow hair (Marcel et al., 2013).

Many studies have confirmed the antimicrobial and fungicidal activities, as well as the antioxidant effect of the anise hyssop (Ownagh et al., 2010). The anise hyssop gives aroma and flavor of a combination of aniseed and mint. Its leaves and flowers are traditionally used either raw or cooked for flavoring many salads, bread, and cooked dishes including 
pea and lamb (Ravindran, 2017). The major constituent of essential oil from $A$. foeniculum is methyl chavicol (estragol) $(88 \%-95 \%)$ which imparts an anise-like flavor and it is usually used in the manufacture of perfumes, liqueurs, some foods, and beer (Mallavarapu et al., 2004; Ravindran, 2017; Zhekova et al., 2010). Based on the analysis of samples obtained from different geographical origins has been suggested the existence of five chemotypes of anise hyssop, 1-the typical estragol-containing one (aniseed-like aroma type), and four others (mint-like aroma type) with other substances as: 2 -menthone (11\%-60\%), 3menthone and pulegone $(6 \%-8 \%), 4-$ methyleugenol, and 5 - methyleugenol and limonene $(3 \%-12 \%)$ (Chumakova and Popova, 2013; Shanayda and Shvydkiv, 2008; Zhekova et al., 2010; Zielińska and Matkowski, 2014).

The aim of the present investigation was gas chromatography-mass spectrometry (GC-MS) analysis of the essential oil obtained from A. foeniculum (Pursh) Kuntze herb and determination of its antioxidant potential, antimicrobial, and acetylcholinesterase inhibitory abilities. The isolation and chemical identification compounds from waste plant material obtained after steam distillation (terpenoids, flavonoids, and phenolic acids) present the additional interest in this research.

\section{MATERIALS AND METHODS}

\section{Plant material and essential oil extraction}

The aerial parts of anise hyssop were purchased from a local drugstore (Dicrassin Ltd., Batch number L02092019, Bulgaria). The plant material was finely ground to powder. The essential oils of dried anise hyssop samples $(75 \mathrm{~g})$ were isolated by steam distillation for 3 hours using a glass Clevenger-type apparatus. The extracted yellow-colored essential oils were dried over anhydrous $\mathrm{Na}_{2} \mathrm{SO}_{4}$ and were kept at a refrigerator $\left(4^{\circ} \mathrm{C}\right)$ in sealed dark glass vials for further analysis. The obtained wastes, as well as the water extract from anise hyssop hydro-distillation, were used for further extraction and analysis.

\section{Extraction procedures}

The aqueous layer after steam distillation was extracted twice with petroleum ether. Then, the aqueous layer was extracted in triplicate with ethyl acetate. The combined ethyl acetate extracts were dried over anhydrous $\mathrm{Na}_{2} \mathrm{SO}_{4}$ and evaporated under vacuum at $45^{\circ} \mathrm{C}$ to dryness. The dried ethyl acetate fraction was dissolved in methanol and it was used for further analyses for phenolic acid by high-performance liquid chromatography with diode-array detection (HPLC-DAD) method. Dried anise hyssop wastes (25 g) were put in a round bottom flask of $250 \mathrm{ml}$ and the plant material was extracted with $100 \mathrm{ml}$ methanol under reflux and boiling for 1 hour. The obtained extract was filtered through filter paper and the residue was extracted again with the same volume of used solvent. Both extracts were combined and then evaporated to dryness. The dry extract was used for analyses of triterpenes by HPLC-DAD method.

\section{GC-MS analysis of essential oil}

GC-MS analysis was carried out on gas chromatograph Agilent Technology Hewlett Packard 7890 A, coupled with MS detector Agilent Technology 5975 C inert XL EI/CI MSD at 70 $\mathrm{eV})$. Separation of the compounds was performed on a column $\mathrm{HP}-5 \mathrm{~ms}(30 \mathrm{~m} \times 0.25 \mathrm{~mm} \times 0.25 \mu \mathrm{m})$ at temperature regime: from $40^{\circ} \mathrm{C}$, held for 3 minutes, then rising at $5^{\circ} \mathrm{C} /$ minute to $300^{\circ} \mathrm{C}$, held for 10 minutes. The injector temperature was set at $250^{\circ} \mathrm{C}$ and the flow rate of helium was $1.0 \mathrm{ml} /$ minute and split 10:1 was used. The injection volume was $1 \mu 1$.The obtained MS spectra were analyzed by 2.64 AMDIS software (NIST, Gaithersburg, MD). Compounds listed in the order of elution from an HP-5ms column with retention indices (RI) determined experimentally by coinjection of C8-C36 alkanes (Ivanov et al., 2018). The identification of the compounds was determined by comparison of mass spectrometry and RI matching on Adams (2001; 2007).

\section{HPLC-DAD analysis of phenolic compounds}

Separations and quantitative determination of polyphenolic content were performed on an HPLC instrument Elite Chrome Hitachi, coupled with a diode-array detector (DAD), and ELITE LaChrom software. The separation was performed on a reverse-phase column Supelco, Discovery ${ }^{\circledR}$ HS C18 (5 $\mu \mathrm{m}, 25$ $\mathrm{cm} \times 4.6 \mathrm{~mm}$ ) at $30^{\circ} \mathrm{C}$, and at wavelength 280 and $320 \mathrm{~nm}$. Elution of polyphenols was achieved with mobile phase $\mathrm{A}-2 \%$ acetic acid and mobile phase B - acetonitrile in gradient mode described before Ivanov et al. (2014) and Marchev et al. (2011) at the flow rate $0.8 \mathrm{ml} / \mathrm{minute}$. The sample injection volume was $20 \mu \mathrm{l}$. For the preparation of the standard curves, the standard pentacyclic triterpenes (ursolic acid, oleanolic acid, betulin, and betulinic acid) purchased from SIGMA (Germany) were used. The identification of components in the sample was performed by comparing their DAD spectrum with the range of DAD spectrum obtained from standards. The yields were mathematically calculated and were represented as milligram per gram extract and milligram per 100 g dry weight (dw).

\section{HPLC-DAD analysis of triterpenes}

Separations and quantitative determination of pentacyclic triterpenes were performed on an HPLC instrument Elite Chrome Hitachi, coupled with a DAD and ELITE LaChrom software. The elution was performed on a reverse-phase column Supelco, Discovery ${ }^{\circledR} \mathrm{HS}$ C18 $(5 \mu \mathrm{m}, 25 \mathrm{~cm} \times 4.6 \mathrm{~mm})$ at $26^{\circ} \mathrm{C}$, with mobile phase methanol: formic acid $(92: 8 \mathrm{v} / \mathrm{v})$ isocratic mode at the flow rate of $0.4 \mathrm{ml} /$ minute. Detection was done at wavelength $210 \mathrm{~nm}$. The sample injection volume was $20 \mu \mathrm{l}$ (Marchev et al., 2012). For the preparation of the standard curves, the standards rosmarinic acid, myricetin, luteolin, and apigenin purchased from SIGMA (Germany) were used. The identification of components in the sample was performed by comparing their DAD spectrum with the range of DAD spectrum obtained from standards. The yields were mathematically calculated and were represented as milligram per gram extract and milligram per $100 \mathrm{~g} \mathrm{dw}$.

\section{Antioxidant activity of essential oil (DPPH method)}

Essential oil in different concentration $(0.15 \mathrm{ml})$ was added to $2.85 \mathrm{ml}$ solution of freshly prepared $0.1 \mathrm{~mol} 1,1$-diphenyl2-picrylhydrazyl radical (DPPH, Sigma) in methanol (Merck, Germany). The reaction was performed for 15 minutes at $37^{\circ} \mathrm{C}$ in darkness. The absorptions were measured at $517 \mathrm{~nm}$ against 
Table 1. GC-MS analysis of anise hyssop essential oil.

\begin{tabular}{llccc}
\hline & Compound & $\begin{array}{c}\text { RI } \\
\text { This study }\end{array}$ & $\begin{array}{c}\text { RI } \\
\text { Adams (2001; 2007) }\end{array}$ & \% of TIC \\
\hline 1 & Sylvestrene & 1,027 & 1,027 & 0.53 \\
2 & 1-octen-3-ol acetate & 1,109 & 1,110 & 0.12 \\
3 & Methyl chavicol (Estragol) & 1,195 & 1,195 & 93.45 \\
4 & Eugenol & 1,355 & 1,356 & 0.15 \\
5 & Methyl isoeugenol & 1,496 & 1,495 & 2.48 \\
6 & ק-Caryophyllene & 1,419 & 1,418 & 1.19 \\
7 & Spathulenol & 1,575 & 1,576 & 0.25 \\
8 & Caryophyllene oxide & 1,580 & 1,581 & 0.60 \\
& Total identified compounds & & & 98.77 \\
\hline
\end{tabular}

methanol. The $\mathrm{IC}_{50}$ value was calculated. The ability of the essential oil to scavenge DPPH radical was calculated as follows:

$$
\text { Inhibition, } \%=\left[\frac{\left(A_{\text {control }}-A_{\text {sample }}\right)}{A_{\text {control }}}\right] * 100
$$

where $A_{\text {control }}$ was absorbance measure for the mixture of methanol and DPPH solution; and $A_{\text {sample }}$ represents absorbance of the different solution of $A$. foeniculum essential oil and DPPH solution.

\section{Test microorganisms for antimicrobial activity}

Eleven microorganisms including five Gram-positive bacteria (Staphylococcus aureus ATCC 25923, Enterococcus faecalis, Curtobacterium flaccumfaciens PM_YT, Listeria monocytogenes, and Bacillus subtilis ATCC 6633); Gramnegative bacteria (Salmonella sp., Escherichia coli ATCC 8739, Proteus vulgaris, Pseudomonas aeruginosa ATCC 9027, and Klebsiella pneumoniae) and yeasts (Candida albicans) from the collection of the Department of Microbiology at the University of Food Technologies, Plovdiv, Bulgaria, were selected for the antimicrobial screening.

\section{Culture media (Luria-Bertani glucose agar)}

Luria-Bertani glucose (LBG) medium was used for the cultivation of test microorganisms and determination of minimal inhibitory concentration (MIC). LBG-agar medium was prepared as follows: $10 \mathrm{~g}$ tryptone, $5 \mathrm{~g}$ yeast extract, $10 \mathrm{~g} \mathrm{NaCl}$, $10 \mathrm{~g}$ glucose, and $15 \mathrm{~g}$ agar in 11 of distilled water. The $\mathrm{pH}$ was adjusted to 7.5 and the medium was sterilized by autoclaving for 20 minutes at $121^{\circ} \mathrm{C}$.

\section{Antimicrobial activity}

The antimicrobial activity of essential oil from anise hyssop (A. foeniculum) was evaluated on LBG-agar medium by the agar well diffusion method (Tumbarski et al., 2017). The test microorganisms were cultured on LBG-agar medium at $37^{\circ} \mathrm{C}$ for 24 hours. The final concentration of the viable cells in the suspensions of sterile $0.5 \% \mathrm{NaCl}$ for inoculation was adjusted to $1.0 \times 10^{8} \mathrm{cfu} / \mathrm{ml}$. Then, the suspensions were inoculated in a preliminarily melted and tempered at $45^{\circ} \mathrm{C}-48^{\circ} \mathrm{C}$ LBG-agar media. The inoculated LBG-agar media were transferred in a volume of $16 \mathrm{ml}$ in sterile Petri dishes $(d=9 \mathrm{~cm})$. After hardening, six wells $(d=6 \mathrm{~mm})$ per dish were cut. A volume of $50 \mu$ l samples were put in the agar wells at duplicated. Antibiotics Streptomycin (6 $\mathrm{mg} / \mathrm{ml})$, Nystatin $(40 \mu \mathrm{g} / \mathrm{ml})$, and methanol were used as controls. The inoculated Petri dishes were incubated at $37^{\circ} \mathrm{C}$. The antimicrobial activity was determined by measuring the diameter of the inhibition zones (ZI) around the wells on the 24th and 48th hour of incubation.

\section{Minimal inhibitory concentration}

MIC of anise hyssop essential oil was determined by the conventional method - series of double-diluted samples, ranging from 10.0 to $0.079 \mu \mathrm{l} / \mathrm{ml}$ were prepared. The Petri dishes were incubated with $50 \mu \mathrm{l}$ at the conditions shown above.

The MIC values were determined as the lowest concentration of the extract inhibiting completely the growth of each test microorganism around the agar well. The determined and recorded MIC values as microliter per milliliter were calculated (Tumbarski et al., 2017).

\section{Acetylcholinesterase inhibitory assay}

Acetylcholinesterase (AChE) inhibitory method was performed by using a colorimetric method described by López et al. (2002) with slight modification: 0.86 U AChE (type VI-S; Sigma) was dissolved in a volume of $1.0 \mathrm{ml} 50 \mathrm{mmol}$ phosphate buffer ( $\mathrm{pH} 8.0$ ), supplied with $0.15 \mathrm{~mol} \mathrm{NaCl}$ and $0.05 \%(\mathrm{v} / \mathrm{v})$ Tween 80 (Duchefa, The Netherlands). Prepared enzyme solution $(20 \mu \mathrm{l})$ was added into $2.0 \mathrm{ml} 50 \mathrm{mmol}$ phosphate buffer ( $\mathrm{pH} 8.0$ ) and mixed with $20 \mu \mathrm{l}$ of analyzed anise hyssop essential oil. The samples were incubated for 20 minutes at $4{ }^{\circ} \mathrm{C}$ in darkness, then the reaction was started by adding $20 \mu \mathrm{l} 6.0 \mathrm{mmol}$ (in $50 \mathrm{mmol}$ phosphate buffer with $\mathrm{pH} 7.0$ ) acetylthiocholine iodide (Sigma) and $20 \mu 15.0 \mathrm{mmol}$ (50 mmol phosphate buffer with $\mathrm{pH}$ 7.0) 5,5'-dithiobis-(2-nitrobenzoic acid) (DTNB, Sigma). Samples were vortexed and incubated at $37^{\circ} \mathrm{C}$ for 20 minutes in darkness. After the reaction time, the samples were cooled down in ice and $20 \mu \mathrm{l}$ of $1.8 \mathrm{mmol}$ (50 mmol phosphate buffer $\mathrm{pH}$ 7.0) Eserine salicylate (Sigma) was added to inactivate the enzyme. A blank sample with pure methanol instead of essential oil was prepared, as well. Positive control samples were developed for both experimental samples and blank sample, following the same procedure, but the enzyme was fully inhibited by adding $20 \mu \mathrm{l}$ of $1.8 \mathrm{mmol}$ eserine salicylate solution before starting the enzyme reaction. Changes in the absorption of samples against their positive controls were measured at $405 \mathrm{~nm}$ wavelength. 


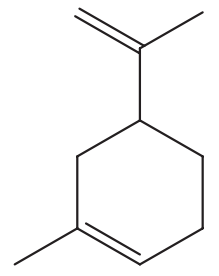

1. Sylvestrene

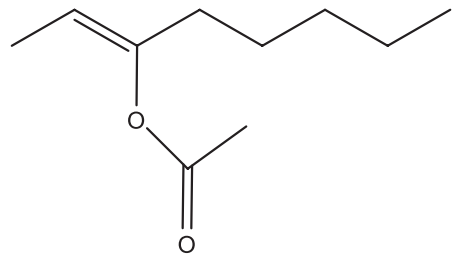

2. 1-octen-3-ol acetate

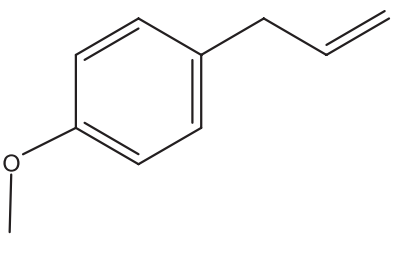

3. Estragol<smiles>C=CCc1ccc(O)c(OC)c1</smiles>

4. Eugenol

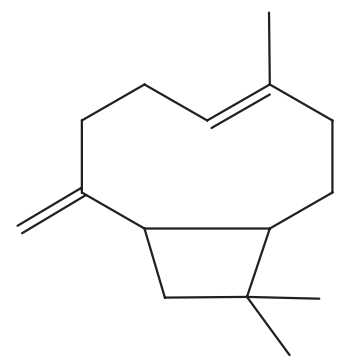

6. $\beta$-Caryophyllene

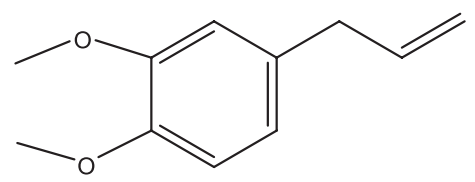

5. Methyl isoeugenol

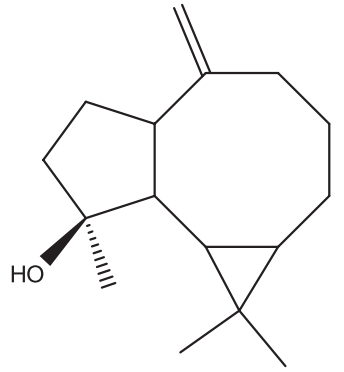

7. Spathulenol

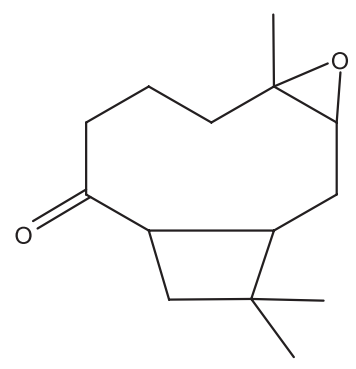

8. Caryophyllene oxide

Figure 1. Chemical structure of identified components in anise hyssop essential oil.

\section{RESULT AND DISCUSSION}

\section{Chemical composition of anise hyssop essential oil}

The GC-MS analysis of the content and composition of essential oil obtained from A. foeniculum (Pursh) Kuntze was presented (Table 1). Three groups of compounds were identified in the essential oil: monoterpenes (sylvestrene and 1-octen-3ol acetate), phenylpropenes (methyl chavicol, eugenol, and methyl isoeugenol), and sesquiterpenes ( $\beta$-caryophyllene, spathulenol, and caryophyllene oxide) (Fig. 1). The essential oil from anise hyssop was found to be transparent yellow liquid with low viscosity and was obtained in a yield of $0.20 \mathrm{~g} / 100 \mathrm{~g}$ dw. The amount of obtained essential oil from $A$. foeniculum was in accordance with results obtained by Charles et al. (1991) (who reported the essential oil content from $0.07 \%$ to $2.45 \%$ ). Eight compounds were detected in anise hyssop essential oils, as one of these compounds Sylvestrene (1) was not previously reported (Fig. 1; Table 1). Methyl chavicol (3) was the major oil component $93.45 \%$ of TIC. Other dominating oil constituents in A. foeniculum included methyl isoeugenol (5) $(2.48 \%)$ and $\beta$-caryophyllene (6) (1.19\%) (Table 1). Moreover, many researchers reported that the essential oil obtained from $A$. foeniculum contained mainly methyl chavicol (from $6 \%$ to $92 \%$ ) regardless of variety, geographical and climatic conditions, and growth phases. $\alpha$-Limonene, menthone, $\beta$-caryophyllene, and germacrene B were established as the plant major constituents (Charles et al., 1991; Myadelets et al., 2013; Nykanen et al., 1989, Shanayda and Shvydkiv, 2008). The anise hyssop has two main chemotypes, as one of them is with aniseed aroma (the methyl chavicol is the main component of the essential oil), and the other with mint aroma tone (mainly presented iso-mentone and pullegone) (Chumakova and Popova, 2013; Shanayda and Shvydkiv, 2008; Zhekova et al., 2010).

In contrast to other authors, the following components of $\alpha$-limonene, menthone, and germacrene B were not identified in the investigated sample. In our case, the investigated essential oil from anise hyssop belonged to an "anethol" type, with aniseed aroma, because it contains methyl chavicol (3) as the main compound (93.45\% of TIC) (Table 1). Mallavarapu et al. (2004) reported that eugenol (4) in the anise hyssop oil was found in higher concentration at the end of their vegetative stage than in oil obtained from plants at full bloom stage. Also, octenol acetate was presented only in the essential oil distilled at the end of the vegetative stage (Mallavarapu et al., 2004). Moreover, it is obvious that the essential oil of anise hyssop plant was comparable in quality to that reported previously. The results of the chemical composition of the anise hyssop essential oil show that the analyzed sample is at the end of the flowering period. Furthermore, the derivatives of estragol which is the major constituent in this oil are usually used in the natural food products as flavorings and perfumes.

\section{Antioxidant activity of anise hyssop essential oil}

The radical scavenging properties of anise hyssop essential oil in a concentration of $10 \mu \mathrm{l} / \mathrm{ml}$ inhibited $77.88 \%$ of DPPH radical (Fig. 2). $\mathrm{IC}_{50}$ of this essential oil was calculated to be $6.45 \mu \mathrm{l} / \mathrm{ml}$. Hashemi et al. (2017) investigated the radicals scavenging activity of essential oil obtained from flowers of $A$. foeniculum. It was analyzed by DPPH assay the $92.1 \%$ of DPPH 


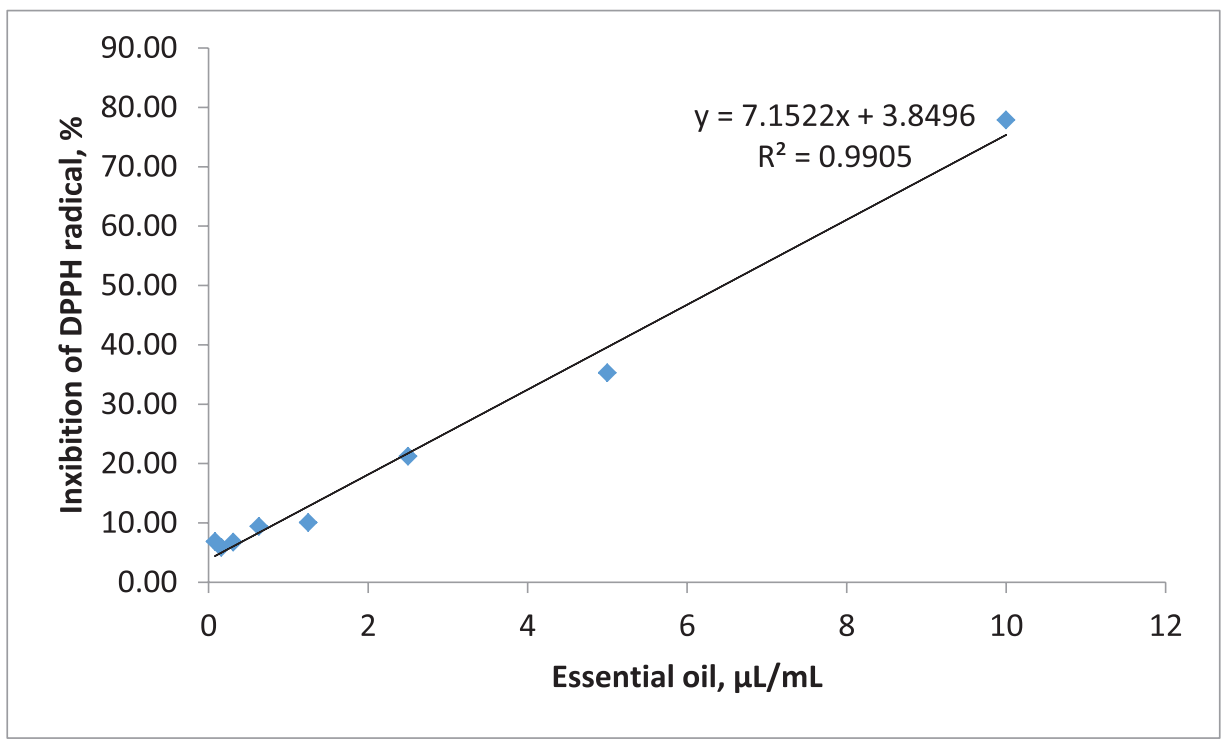

Figure 2. Antioxidant activity (DPPH radical scavenging ability) of anise hyssop essential oil.

Table 2. Antimicrobial activity of essential oil obtained from aerial parts of A. foeniculum.

\begin{tabular}{|c|c|c|c|c|}
\hline \multirow[b]{2}{*}{ Test microorganisms } & \multicolumn{2}{|c|}{ Antimicrobial activity } & \multicolumn{2}{|c|}{ Antibiotics } \\
\hline & $\mathrm{ZI}^{*}, \mathbf{m m}$ & $\begin{array}{l}\mathrm{MIC}, \\
\mu \mathrm{I} / \mathrm{ml}\end{array}$ & $\begin{array}{l}\text { Streptomycin, } \\
6 \mathrm{mg} / \mathrm{ml}\end{array}$ & $\begin{array}{l}\text { Nystatin, } \\
40 \mu \mathrm{g} / \mathrm{ml}\end{array}$ \\
\hline \multicolumn{5}{|l|}{ Gram-positive bacteria } \\
\hline Staphylococcus aureus ATCC 25923 & $10 \pm 0.3$ & 1.25 & $27 \pm 0.3$ & na \\
\hline Enterococcus faecalis & - & - & $21 \pm 0.3$ & na \\
\hline Listeria monocytogenes & $10 \pm 0.3$ & 1.25 & $22 \pm 0.3$ & na \\
\hline Bacillus subtilis ATCC 6633 & $10 \pm 0.3$ & 0.625 & $30 \pm 0.3$ & na \\
\hline Curtobacterium flaccumfaciens & $8 \pm 0.3$ & 2.50 & $33 \pm 0.3$ & na \\
\hline \multicolumn{5}{|l|}{ Gram-negative bacteria } \\
\hline Escherichia coli ATCC 8739 & $10 \pm 0.6$ & 0.313 & $17 \pm 0.3$ & \\
\hline Pseudomonas aeruginosa ATCC 9027 & $10 \pm 0.6$ & 0.157 & $23 \pm 0.3$ & na \\
\hline Proteus vulgaris & $10 \pm 0.3$ & 1.25 & $17 \pm 0.3$ & na \\
\hline Salmonella sp. & $10 \pm 0.3$ & 1.25 & $12 \pm 0.3$ & na \\
\hline Klebsiella pneumoniae & $10 \pm 0.3$ & 0.625 & $16 \pm 0.3$ & na \\
\hline \multicolumn{5}{|l|}{ Yeasts } \\
\hline Candida albicans & $10 \pm 0.3$ & 0.157 & na & 13 \\
\hline
\end{tabular}

radical was inhibited in a concentration of $10 \mathrm{mg} / \mathrm{ml}$ (Hashemi et al., 2017).

\section{Antimicrobial activity of anise hyssop essential oil}

Antimicrobial activity is among the most frequently reported properties of essential oils from different Lamiaceae plants. The results from antimicrobial screening demonstrated that the essential oil of $A$. foeniculum in a concentration of 10 $\mu \mathrm{l} / \mathrm{ml}$ possessed moderate inhibitory effect on Gram-positive bacteria $S$. aureus ATCC 25923, C. flaccumfaciens PM_YT, L. monocytogenes, B. subtilis ATCC 6633, Gram-negative Salmonella sp., E. coli ATCC 8739, P. vulgaris, P. aeruginosa ATCC 9027, K. pneumoniae and yeasts $C$. albicans, while Grampositive bacterium $E$. faecalis remained unaffected. The inhibitory activity of the essential oil of $A$. foeniculum against the test microorganisms was lower compared to the antibiotics served as controls. Methanol used as solvent showed negative results (Table 2).

The MIC values, summarized in Table 2, showed that the test microorganisms were sensitive to very low concentrations of the tested oil, ranging from $0.157 \mu \mathrm{l} / \mathrm{ml}$ for P. aeruginosa ATCC 9027 and C. albicans to $2.5 \mu \mathrm{l} / \mathrm{ml}$ for $C$. flaccumfaciens PM_YT, respectively. At present, there are inadequate data in the scientific literature for the antimicrobial activity of anise hyssop essential oil, although these plants are widespread and famous from the ancient times with their healing properties. Some authors reported that strength of antibacterial and antifungal activity of Agastache essential oil was rather to moderate in all the studied species. Antimicrobial and antifungal activities against $S$. aureus, L. monocytogenes, Bacillus cereus, $B$. subtilis, Salmonella typhimurium, Salmonella enteritidis, E. coli, Aspergillus niger, and Aspergillus flavus were investigated of 
Table 3. Acetylcholinesterase inhibitory activity of essential oil (EO) from A. foeniculum and positive standard galanthamine.

\begin{tabular}{|c|c|c|}
\hline \multirow[b]{2}{*}{ Sample } & \multicolumn{2}{|c|}{ Acetylcholinesterase inhibitory activity } \\
\hline & $\begin{array}{c}\text { Inhibition, \%, } \\
10 \mu \mathrm{E} \text { EO/ml }\end{array}$ & $\begin{array}{c}\mathrm{IC}_{50}, \\
\mathrm{mg} \mathrm{EO} / \mathrm{l}\end{array}$ \\
\hline Anise hyssop essential oil & $18.20 \pm 1.70$ & $19.25 \pm 0.02$ \\
\hline Standard & & $\mathrm{IC}_{50} \mathrm{mg} / \mathrm{l}$ \\
\hline Galanthamine & - & $6.62 \pm 0.05$ \\
\hline
\end{tabular}

Table 4. Pentacyclic triterpenes identified in methanol extract obtained from anise hyssop waste by HPLC-DAD.

\begin{tabular}{lcc}
\hline Pentacyclic triterpenes & Extract $(\mathbf{m g} / \mathbf{g})$ & Dry weight $\mathbf{( m g / \mathbf { 1 0 0 }} \mathbf{~})$ \\
\hline Betulin & $36.1 \pm 1.1$ & $105.8 \pm 2.0$ \\
Betulinic acid & $92.4 \pm 0.5$ & $270.2 \pm 3.2$ \\
Oleanolic acid & $160.0 \pm 2.7$ & $468.3 \pm 5.2$ \\
Ursolic acid & $6.7 \pm 0.1$ & $19.6 \pm 0.5$ \\
\hline
\end{tabular}

essential oil from anise hyssop (Hashemi et al., 2017). However, essential oil from Agastache rugosa possessed antifungal activity (Shin, 2004; Shin and Kang, 2003). Our results for the antimicrobial potential of essential oil obtained from the aerial part of $A$. foeniculum enriched the application of this plant in cosmetic and food industries.

\section{Acetylcholinesterase inhibition of essential oil}

The summary of acetylcholinesterase inhibition (AChEI) of essential oil and the standard galanthamine used in this study was given in Table 3. The AChEI of this essential oil was indicated primarily by its $\mathrm{IC}_{50}$. From the $\mathrm{IC}_{50}$ of $A$. foeniculum, essential oil showed an AChEI capacity similar to that of the reference inhibitor galantamine (Table 3). In the available scientific literature, no data are available for acetylcholinesterase inhibitory activity of $A$. foeniculum essential oil $\left(\mathrm{IC}_{50} 19.25 \mathrm{mg} / \mathrm{l}\right)$. Similar results for acetylcholinesterase inhibitory activity of essential oil from different medicinal plants of Aframomum melegueta $\left(\mathrm{IC}_{50} 16.0 \mathrm{mg} / \mathrm{l}\right)$, Crassocephalum crepidioides $\left(\mathrm{IC}_{50} 12.1 \mathrm{mg} / \mathrm{l}\right)$, Monodora myristica $\left(\mathrm{IC}_{50} 15.6 \mathrm{mg} / \mathrm{l}\right)$, and Ocimum gratissimum $\left(\mathrm{IC}_{50} 6.54 \mathrm{mg} / \mathrm{l}\right)$ were found (Owokotomo et al., 2015). The acetylcholinesterase inhibitory activity is due to synergistic and antagonistic interactions between the components of essential oil. Major compound in anise hyssop essential oil was estragol (Table 1). This compound was reported to possess high AChE inhibition activities $\left(\mathrm{IC}_{50} 0.337 \mu \mathrm{mol}\right)$, followed by eugenol as well $\left(\mathrm{IC}_{50}\right.$ $40.32 \mu \mathrm{mol})$ (Farag et al., 2016).

\section{Evaluation of wastes after steam distillation}

After steam distillation of anise hyssop, aerial parts for production of essential oil, the waste and aqueous extract were used for analysis. Methanol as solvents and the extraction under reflux for the extraction and isolation of pentacyclic triterpenes was applied. The yield of extract was calculated as $-2.9 \pm 0.1 \mathrm{~g} / 100 \mathrm{~g}$ dw. In the present study, for the first time, these compounds were analyzed and the individual triterpenic acids in anise hyssop waste were identified. Four terpenoids - betulin, betulinic, oleanolic, and ursolic acids - were found in anise hyssop as oleanolic and betulinic acids were in high concentrations: oleanolic acid- 160.0 $\mathrm{mg} / \mathrm{g}$ extract $(468.3 \mathrm{mg} / 100 \mathrm{~g} \mathrm{dw})$ and betulinic acid-92.4 $\mathrm{mg} / \mathrm{g}$ extract $(270.2 \mathrm{mg} / 100 \mathrm{~g} \mathrm{dw})$, respectively (Table 4). That
Table 5. Phenolic compounds identified in the aqueous extract obtained from steam distillation of anise hyssop by HPLC-DAD.

\begin{tabular}{lcc}
\hline Compounds & $\begin{array}{c}\text { Extract } \\
(\mathbf{m g} / \mathbf{g})\end{array}$ & $\begin{array}{c}\text { Dry weight } \\
(\mathbf{m g} / \mathbf{1 0 0} \mathbf{g})\end{array}$ \\
\hline Phenolic acid & & \\
Rosmarinic acid & $50.6 \pm 0.5$ & $177.1 \pm 1.4$ \\
Flavonoids & & \\
Myricetin & $0.5 \pm 0.1$ & $1.6 \pm 0.3$ \\
Luteolin & $0.9 \pm 0.1$ & $3.2 \pm 0.3$ \\
Apigenin & $0.6 \pm 0.1$ & $2.0 \pm 0.2$ \\
\hline
\end{tabular}

was of the great importance because of many valuable biological activities of these terpenoids (Jäger et al., 2009). Indeed, this class of compounds presents several biological activities, including anti-inflammatory (Pádua et al., 2014), antioxidant (Smina et al., 2011), anti-viral (Cichewicz and Kouzi, 2004), anti-diabetic (Alqahtani et al., 2013), anti-tumor (Laszczyk, 2009), hepatoprotective (Prasad et al., 2007), and cardio-protective (Shaik et al., 2012) activities. Due to the revealed pentacyclic triterpenes profile of anise hyssop waste, they showed the potential for application in cosmetic and food formulas.

From investigated water extracts, the highest yield of rosmarinic acid $(50.6 \mathrm{mg} / \mathrm{g}$ extract) and the various number of flavonoids with high biological activity (myricetin $-0.45 \mathrm{mg} / \mathrm{g}$, luteolin $-0.92 \mathrm{mg} / \mathrm{g}$, and apigenin $-0.57 \mathrm{mg} / \mathrm{g}$,) was detected (Table 5).Therefore, anise hyssop waste after steam distillation could be used as a promising source of extracts (yield $3.5 \pm 0.2$ $\mathrm{g} / 100 \mathrm{~g} \mathrm{dw}$ ) with high biological value for the application in pharmaceutical and cosmetic sectors. The similar result has been obtained from anise hyssop aerial parts cultivated in Egypt from Mostafa et al. (2018), they were identified coumarin, ferulic acid, rutin, and luteolin and apigenin.

\section{CONCLUSION}

The information for medicinal uses and phytochemical compounds in essential oil and waste plant material from $A$. foeniculum aerial parts were enriched. This is the first report of its kind to present acetylcholinesterase inhibitory activity of A. foeniculum essential oil $\left(\mathrm{IC}_{50} 19.25 \mathrm{mg} / \mathrm{l}\right)$. Moreover, for the first time, the presence of betulin, betulinic acid, and oleanolic acid in anise hyssop waste and sylvestrene (1) in essential oil were detected and reported by us. The obtained essential oil from A. foeniculum possessed strong antioxidant and moderate antimicrobial and acetylcholinesterase inhibitory activity. The phytochemical compounds in different extracts could found possible application in the pharmaceutical industry and also for the natural cosmetic products.

\section{REFERENCES}

Adams RP. Identification of essential oil components by gas chromatography/quadrupole mass spectroscopy. Allured Publishing Corporation, Carol Stream, IL, 2001.

Adams RP. Identification of essential oils components by gas chromatography mass spectroscopy. 4th edition, Allured Pubishing Corporation, Carol Stream, IL, 2007.

Alqahtani A, Hamid K, Kam A, Wong K, Abdelhak Z, Razmovski-Naumovski V, Chan K, Li K, Groundwater P, Li G. The pentacyclic triterpenoids in herbal medicines and their pharmacological activities in diabetes and diabetic complications. Curr Med Chem, 2013; 20:908-31. 
Charles DJ, Simon JE, Glowacki C, Widrlechner MP. Characterization of essential oil of Agastache species. J Agric Food Chem, 1991; 39(11):1946-9.

Chumakova VV, Popova OI. Lofant anisovy (Agastache foeniculum L.). A perspective source of obtaining drugs. Pharm Pharmacol, 2013; 1:39-43 (on Russian).

Cichewicz R, Kouzi S. Chemistry, biological activity, and chemotherapeutic potential of betulinic acid for the prevention and treatment of cancer and HIV infection. Med Res Rev, 2004; 24:90-114.

Farag MA, Ezzat SM, Salama MM, Tadros MG, Serya RAT. Antiacetylcholinesterase activity of essential oils and their major constituents from four Ocimum species. Z Naturforsch C, 2016; 71(11-12):393-402.

Hashemi M, Ehsani A, Hassani A, Afshari A, Aminzare M, Sahranavard T, Azimzadeh Z. Phytochemical, antibacterial, antifungal and antioxidant properties of Agastache foeniculum essential oil. JCHR, 2017; 7(2):95-104.

Ivanov I, Dincheva I, Badjakov I, Petkova N, Denev P, Pavlov A. GC-MS analysis of unpolar fraction from Ficus carica L. (fig) leaves. IFRJ, 2018; 25(1):282-86.

Ivanov I, Vrancheva R, Marchev A, Petkova N, Aneva I, Denev P, Georgiev V, Pavlov A. Antioxidant activities and phenolic compounds in Bulgarian Fumaria species. Int J Curr Microbiol App Sci, 2014; 3(2):296-306.

Jäger S, Trojan H, Kopp T, Laszczyk MN, Scheffler A. Pentacyclic triterpene distribution in various plants - rich sources for a new group of multi-potent plant extracts. Molecules, 2009; 14:2016-31.

Laszczyk M. Pentacyclic triterpenes of the lupane, oleanane and ursane group as tools in cancer therapy. Planta Med, 2009; 75:1549-60.

López S, Bastida J, Viladomat F, Codina C. Acetylcholinesterase inhibitory activity of some alkaloids and Narcissus extracts. Life Sci, 2002; 71:2521-9.

Mallavarapu GR, Kulkarni RN, Baskaran K, Ramesh S. The essential oil composition of anise hyssop grown in India. Flavour Fragr J, 2004; 19:351-3.

Marcel DM, Vârban DI, Muntean S, Moldovan C, Olar M. Use of species Agastache foeniculum (Pursh) Kuntze. Hop Med Plant, 2013; $2: 41-2$.

Marchev A, Georgiev V, Ivanov I, Badjakov I, Pavlov A Two-phase temporary immersion system for Agrobacterium rhizogenes genetic transformation of Salvia tomentosa Mill. Biotechnol Lett, 2011; 33(9):1873-8

Marchev A, Ivanov I, Georgiev V, Pavlov A. Determination of di- and triterpenes in Salvia tomentosa Mill. cell suspension culture by high performance liquid chromatography. Sci Works UFT, 2012; 59:229-33.

Mostafa EM, Abdelhady NM, El-Hela AA. Phytochemical and biological activity of Agastache foeniculum (Pursh) Kuntze cultivated in Egypt. JCBPSC, 2018; 8(2):434-43.

Tumbarski Y, Lincheva V, Petkova N, Nikolova R, Vrtancheva R, Ivanov I. Antimicrobial activity of extract from aeral parts of potentilla (Potentilla reptans L.). Ind Technol, 2017; 4(1):37-43.

Myadelets MA, Vorobyeva TA, Domrachev DV. Composition of the essential oils of some species belonging to genus Agastache Clayton ex Gronov (Lamiaceae) cultivated under the conditions of the Middle Ural. Chem Sust Devel, 2013; 21:397-401.
Nykanen I, Holm Y, Hiltunen R. Characterization of essential oil of Agastache foeniculum. Planta Med, 1989; 55:314-5.

Ownagh AO, Hasani A, Mardani K, Ebrahimzadeh S. Antifungal effects of thyme, agastache and satureja essential oils on Aspergillus fumigatus, Aspergillus flavus and Fusarium solani. Vet Res Forum, 2010; 1(2):99-105.

Owokotomo IA, Ekundayo O, Abayomi TG, Chukwuka AV. In vitro anti-cholinesterase activity of essential oil from four tropical medicinal plants. Toxic Rep, 2015; 2:850-7.

Pádua T, de Abreu B, Costa T, Nakamura M, Valente L, Henriques M, Siani A, Rosas E. Anti-inflammatory effects of methyl ursolate obtained from a chemically derivedcrude extract of apple peels: potential use in rheumatoid arthritis. Arch Pharm Res, 2014; 37:1487-95.

Prasad S, Kalra N, Shukla Y. Hepatoprotective effects of lupeol and mango pulp extract of carcinogen induced alteration in Swiss albino mice. Mol Nutr Food Res, 2007; 51:352-9.

Ravindran PN. The encyclopedia of herbs and spices, 11. Anise Hysspo Agastache foeniculum. CAB International, UK, 2017.

Shaik A, Rasool S, Abdul Kareem M, Krushna G, Akhtar P, Devi $\mathrm{K}$. Maslinic acid protects againstisoproterenol-induce cardiotoxicity in albino Wistar rats. J Med Food, 2012; 15:741-6.

Shanayda MI, Shvydkiv OS. Comparative analysis of essential oils of two forms of Lophanthus anisatus Adans. Phytochem Res, 2008; 2:56-60 (On Ukraine)

Shin S. Essential oil compounds from Agastache rugosa as antifungal agent against Trichophyton species. Arch Pharm Res, 2004; 27:295-9

Shin S, Kang CA. Antifungal activity of the essential oil of Agastache rugosa Kuntze and its synergism with ketoconazole. J Appl Microbiol, 2003; 36:111-5.

Smina T, Mathew J, Janardhanan K, Devasagavam T. Antioxidant activity and toxicity profile of total triterpenes isolated from Ganoderma lucidum (Fr.) P. Karst occurring in South India. Environ Toxicol Pharmacol, $2011 ; 32: 438-46$

Zhekova G, Dzhurmanski A, Dobreva A. Gas-chromatography and organoleptic analysis of the essential oil of Agastache foeniculum (Pursh.) Kuntze. Agric Sci Technol, 2010; 2(2):102-4.

Zielińska S, Matkowski A. Phytochemistry and bioactivity of aromatic and medicinal plants from the genus Agastache (Lamiaceae) Phytochem Rev, 2014; 13:391-416.

\section{How to cite this article:}

Ivanov IG, Vrancheva RZ, Petkova NT, Tumbarski Y, Dincheva IN, Badjakov IK. Phytochemical compounds of anise hyssop (Agastache foeniculum) and antibacterial, antioxidant, and acetylcholinesterase inhibitory properties of its essential oil. J Appl Pharm Sci, 2019; 9(02):072-078. 